\title{
Mice selected for large and small brain weight: The preservation of trait differences after the selection was discontinued
}

\author{
Olga V. Perepelkina, Vassilissa A. Golibrodo, Irina G. Lilp, Inga I. Poletaeva \\ Laboratory of Physiology and Genetics of Behavior, Chair of Higher Nervous Activity, Biology Faculty, Lomonossov Moscow State \\ University, Moscow, Russia \\ Email: ingapoletaeva@mail.ru
}

Received 11 April 2013; revised 13 May 2013; accepted 25 May 2013

Copyright (C) 2013 O. V. Perepelkina et al. This is an open access article distributed under the Creative Commons Attribution License, which permits unrestricted use, distribution, and reproduction in any medium, provided the original work is properly cited.

\begin{abstract}
The selection for large and small relative brain weight (RBW) in mice, started in 1999, resulted in stable significant differences in the trait (16\%). The selection was discontinued at F22, and both lines (Large Brain, LB and Small brain, SB) were maintained by random mating. In F25-F28 the significant differences in RBW were still present in spite of the lack of selection. In F28 ethanol injections $(2.4 \mathrm{mg} / \mathrm{kg}$, $12 \%$ ethanol, i.p.) were performed to animals of both lines. The ethanol effects were more intense in SB, than in LB line. Mice were tested in elevated and closed plus-mazes and in slip-funnel tests. Control LB mice explored new environment more actively and were less affected by stressful environment than SBs. SB ethanol mice were less anxious in elevated plus maze, initiated closed maze exploration earlier, moved more vividly and demonstrated lower anxiety level in elevated plus maze than saline injected mice, while changes in these behaviors after ethanol were not so clear in LB mice, although their locomotion level increased.
\end{abstract}

Keywords: Selection; Brain Weight; Ethanol Effects; Anxiety; Exploration; Cross Mazes

\section{INTRODUCTION}

Relative brain weight (the brain/body weight ratio, RBW), used in comparative neurology for revealing possible interspecies differences, is at the same time the indicator of species evolutionary level [1-3]. Genetic and environmental factors and their interactions influence this parameter demonstrating the complex nature of this trait $[4,5]$. Brain weight changes as the result of envi- ronmental enrichment were also reported. The significant decrease in brain weight in laboratory rodents was found as the result of prenatal exposure of animals to different physical and chemical agents [6,7]. Experimental data indicate, that the RBW (and the number of brain cellular elements) is the factor that influences animal behavioral performance in laboratory tests. The genetic variability of RBW was proved to exist, and it was possible to select mouse lines diverging by this trait [5,9-11]. Differences in the RBW between the selected mouse lines and correlation of this trait with different behavioral traits could be used as the putative model for relationships of morphological and physiological traits $[9,10,12,13]$.

The RBW variability was studied mainly in laboratory mice $[5,14,15]$ and more rarely in rats [16]. Selection for large and small RBW resulted in the inter strain differences after few generations $[7,9,18,19]$. Large and Small Brain mice lines (LB and SB, respectively) were bred in our laboratory in three successive selection experiments (SE), the last one starting in 1999 [17-20]. In the first and second SEs the selection started using the genetically heterogeneous population of $\mathrm{F} 4$ cross of 6 inbred strains (C57/BL6/J, C57BR/J, CBA/Lac-Sto, DBA/2J, BALB/c and $\mathrm{A} / \mathrm{He}$ from Stolbovaya Center), while the third SE was performed on the basis of $\mathrm{F} 2$ hybrid population derived from LB and SB crosses of the 2d SE. In the 1st SE the differences in the size of cortical structures and in number of neocortical cellular elements were found [21]. The scores for total cortical area were larger in LB (by $18 \%$ ), with differences documented for neo- cortex $(22 \%)$ and archicortex (17\%), but not for paleo- cortex. The differences in the spatial distribution of cor- tical cells in LB and SB brains were demonstrated as well. In LB's cortical structures the areas with compactly packed cells alternated with patches of less densely packed cellular elements, while in SB cortical fields the cell pack- 
ing was homogenous [21].

Learning capacity differences in mice selected for large and small RBW (in independent selection experiments from different laboratories) were demonstrated. In all cases mice, selected for LB, learned more efficiently than SB's [10,20,22-25]. In LB and SB mice from our selection experiments differences in learning were shown for both-food reinforced [18] and passive avoidance paradigms [25]. Fuller BWS lines differed also in aggression [7]. The LB-SB differences were noted for exploration, stress reactivity and anxiety tests in LB and SB mice [17].

This paper presents data on the conservation of relative brain weight differences between two lines selected for this trait after the selection stopped and animals were bred at random inside each of the line during 6 generations.

In previous study (data not presented) [26] mice from LB and SB lines demonstrated differences in the behavioral effects of ethanol. These differences, verified using data for F2 LB-SB hybrids, were shown to be at least partly genotype dependent. This paper presents data on ethanol tolerance in mice of LB and SM lines after the discontinuation of selection for morphological trait.

\section{METHODS AND MATERIAL}

The procedure of initial RBW selection was the fol- ing. The parents for the next generation (1 male and $3-4$ females) were mated, being placed in the plastic cages $(32.5 \times 21.5 \times 10 \mathrm{~cm})$. There were usually $10-15$ families in each line in each generation. The pregnant females were isolated from males and the number of pups in the litter was culled to 7 . If litter size was less than 4 the whole litter was discarded. Male and female mice were separated at the age of $25-30$ days and kept in cages by $5-8$ per cage. At the age of $60-70$ days one half of mice from the given litter were sacrificed (lethal ether anesthesia) and the RBW determined. The regres- sion line between body and brain weights was plotted for each generation for individual scores. The regression line of body-brain weight served to determine whether this litter will be used for further selection or it should be discarded [19]. In parental groups the inbreeding was avoided.

Discontinuation of selection. Starting from F22 the plausible parents for the next generation (4 males and 6 females) were chosen by chance and placed in larger cages $(34 \times 29 \times 17 \mathrm{~cm})$, litters sizes were left "nonculled". In F23-25 generations the RWBs of LB and SB mice were not determined. In F25-28 the brain weight was measured (see Table 1), although the choice of breeding pairs for the next generation was determined at random.

Experimental animals. F28 male mice were used for behavior investigation. The effects of ethanol and saline

Table 1. Mean brain and body weighs in Large brain and Small brain mice (LB and SB) during the selection and after its discontinuation.

\begin{tabular}{|c|c|c|c|c|c|c|}
\hline Generation & Line & $\mathrm{N}$ & Body weight, g & $\mathrm{p} \leq$ & Brain weight, mg & $\mathrm{p} \leq$ \\
\hline \multirow{2}{*}{ F5 } & LB & 54 & $22.06 \pm 0.26$ & \multirow{2}{*}{0.99} & $438 \pm 3.66$ & \multirow{2}{*}{0.042} \\
\hline & SB & 30 & $22.03 \pm 0.34$ & & $426.43 \pm 4.75$ & \\
\hline \multirow{3}{*}{ F6 } & LB & 48 & $19.78 \pm 0.36$ & \multirow{3}{*}{0.33} & $436.6 \pm 4.06$ & \multirow{3}{*}{0.11} \\
\hline & SB & 47 & $20.33 \pm 0.48$ & & $428.12 \pm 3.38$ & \\
\hline & SB & 27 & $23.48 \pm 0.73$ & & $406.51 \pm 3.93$ & \\
\hline \multirow{2}{*}{ F18 } & LB & 47 & $29.2 \pm 0.59$ & \multirow{2}{*}{0.00003} & $511.2 \pm 4.1$ & \multirow{2}{*}{$10^{-7}$} \\
\hline & SB & 45 & $25.7 \pm 0.57 \Gamma$ & & $419.2 \pm 4.3$ & \\
\hline \multirow{2}{*}{ F19 } & LB & 44 & $26.3 \pm 0.5$ & \multirow{2}{*}{0.0003} & $504.1 \pm 5.3$ & \multirow{2}{*}{$10^{-7}$} \\
\hline & SB & 36 & $23.2 \pm 0.6$ & & $409.3 \pm 3.6$ & \\
\hline \multirow{2}{*}{ F22 } & LB & 23 & $21.1 \pm 0.5$ & \multirow{2}{*}{0.00002} & $481.9 \pm 5.8$ & \multirow{2}{*}{$10^{-6}$} \\
\hline & SB & 22 & $17.3 \pm 0.4$ & & $400.5 \pm 3.5$ & \\
\hline \multirow{2}{*}{$\mathrm{F} 25^{*}$} & LB & 28 & $28.4 \pm 1.1$ & \multirow{2}{*}{0.2} & $490.2 \pm 5.9$ & \multirow{2}{*}{$10^{-7}$} \\
\hline & SB & 34 & $28.3 \pm 0.8$ & & $402.1 \pm 3.9$ & \\
\hline \multirow{2}{*}{$\mathrm{F} 26-27^{*}$} & LB & 12 & $30.0 \pm 0.7$ & \multirow{2}{*}{0.09} & $465.2 \pm 6.4$ & \multirow{2}{*}{$10^{-5}$} \\
\hline & SB & 16 & $28.5 \pm 0.5$ & & $414.4 \pm 4.5$ & \\
\hline \multirow{2}{*}{$\mathrm{F} 28^{*}$} & LB & 11 & $29.7 \pm 1.2$ & \multirow{2}{*}{0.6} & $485.8 \pm 11.6$ & \multirow{2}{*}{$10^{-6}$} \\
\hline & SB & 17 & $29.9 \pm 0.7$ & & $391.7 \pm 3.2$ & \\
\hline
\end{tabular}

"brain and body weights after the discontinuation of selection for this morphological trait. 
injections on several behavioral indices were determined. In LB group there were 9 mice for experimental group and 8 for controls. In SB there were 12 and 9 mice respectively.

Ethanol injections. $2.4 \mathrm{mg} / \mathrm{kg}$ of $12 \%$ ethanol (approximately $0.3 \mathrm{ml}$ ) was injected i.p. $20 \mathrm{~min}$ before the behavioral tests. The control animals were injected with the respective saline volume.

Behavior. 2 types of cross-maze tests as well as "slip funnel" test were performed. Animals were tested during the same time of the day-11:00 a.m.-15:00 p.m.

All experiments were performed in accordance with the bioethical rules of EC 2010 Declaration. The protocols were approved by Moscow State University Ethical Committee.

Behavioral tests. The elevated plus-maze device (EPM) (arm width $-5 \mathrm{~cm}$, arm length-25) was elevated for $40 \mathrm{~cm}$ above the floor surface. The test lasted for 3 min. The numbers of open arms entries, passages between closed arms, hangings from open arm, rearings, defecations and peeping out of the closed arms were scored manually.

The closed plus-maze test. The cross-maze apparatus was made of Plexiglas and consisted of four closed empty arms (numbered 1, 2, 3, 4 with sizes $15 \times 15 \times 15$ $\mathrm{cm}$ ) connected to a similar central compartment via $7 \times 7$ $\mathrm{cm}$ doorways. The animal was placed into the central compartment and allowed to explore the maze. The sequence and timing of arm visits were recorded directly into a PC until 13 visits had been made ("visit" was the entry with all four paws). Subsequent computer analysis was made to reveal several independent behavioral measures [27]. Those important for the present investigation are listed below: 1) time in arms; 2) the arm visited first (serves as locomotion and exploration measure, this variable was shown to correlate highly and negatively with open field locomotion [28]); 3) latency to start exploration, i.e., the time spent in the center before the first arm entry, which correlated negatively with the total time in the open arms in the elevated plus-maze test [27]; 4) the duration of the first episode of maze patrolling, i.e., the number of entries performed by an animal until all four arms have been visited (for instance, if the armentering sequence for the 13 entries was $1,241,413$ 344,321 , then the length of first patrolling is seven, because initial total maze exploration was completed with entry into arm 3 on visit 7 . The more visits for patrolling episode takes, the less efficient the exploration is considered to be with optimal patrolling requiring only 4 visits); 5) the total number of patrolling episodes made by an animal during the test, as the measure of exploration (the variables 3 and 4 highly correlate with open-field exploratory activity [28]); 5) when animal visited two arms in an alternating manner it was scores as stereo- typed visits, in the example above only four stereotyped visits were performed.

Inescapable Slip Funnel apparatus used for this test consisted of an upper cylindrical portion with vertical walls ( $8 \mathrm{~cm}$ high, $27.5 \mathrm{~cm}$ in diameter), a center funnel section $(9.5 \mathrm{~cm}$ high) with walls sloping inward (at angle of $\left.40^{\circ}\right)$, and a lower vertical cylindrical portion $(4 \mathrm{~cm}$ high, $4.5 \mathrm{~cm}$ in diameter). Water $\left(22^{\circ} \mathrm{C}\right)$ filled the bottom cylinder to the level that hind legs of a "standing" mouse were in the water. The animal was placed into the water and observed for $3 \mathrm{~min}$. Using a PC program, the time of the following behaviors was recorded: 1) immobility in the water at the bottom, correlated positively with immobility scores in the forced swim test [27]; 2) climbing out of the water and sitting in a sprawling posture on sloping wall outside the water surface - a measure of water avoidance; 3 ) attempts of climbing and jumping to get out of the funnel-a measure of active escape attempts, negatively correlated with immobility in the forced swim test [27].

Statistical Analysis. The data obtained were processed by the use of STATISTICA 6 program. The statistical test employed was the 2-factor ANOVA with Fisher LSD post hoc.

\section{RESULTS}

Selection data for generations presented in the Table 1 show significant $(\mathrm{p} \leq 0.042)$ LB-SB differences starting from F5. Differences became larger as the selection proceeded and in F22 they were highly significant (16\% of the mean brain weight in total).

Brain weight in the randombred generations of $\mathbf{L B}$ and SB lines. In F25-28 the brain weights differences were found to be also highly significant (for absolute values see Table 1). There was the slight decrease in the brain weights (but not in body weights) scores in LB line in comparison to previous selection generations. This trend could be the result of larger sizes of litters in LB (data not presented) - as litter sizes were not culled in these generations. It could be that the nurture level in the pre-weaning period in these mice could be lower because of this, and affected brain size.

Ethanol injection effects. The EPM performance (Table 2). The LB control mice demonstrated the significantly larger number of peepings out of the closed arms than SB, and higher number of rearings in the closed arms. The most other indices of behavior in EPM in control animals indicated the higher anxiety level in SB mice. although differences being non-significant (due to small group sizes). SB ethanol injected mice spent significantly more time in open arms, than SB controls, while in LBs the similar difference was not significant.

The same differences were found for open arm entries 
Table 2. Behavior of F28 LB and SB mice in the EPM after ethanol or saline injections.

\begin{tabular}{ccccc}
\hline Behavioral indices & LB ethanol & LB saline & SB ethanol & SB control \\
\hline Open arms time. Sec & $25.6 \pm 7.7$ & $10.0 \pm 6.5$ & $23.5 \pm 5.1^{* *}$ & $2.3 \pm 0.9$ \\
Open arms entries & $2.6 \pm 0.7$ & $1.1 \pm 0.7$ & $2.3 \pm 0.5^{* *}$ & $0.2 \pm 0.1$ \\
Alternating (closed arms) & $1.6 \pm 0.6$ & $0.6 \pm 0.3$ & $1.0 \pm 0.3^{*}$ & 0 \\
Peepings from closed arm & $5.8 \pm 0.8$ & $4.4 \pm 0.9^{\#}$ & $6.1 \pm 0.5^{* * *}$ & $1.4 \pm 04$ \\
Hangings from open arms & $3.8 \pm 1.2^{\text {\&\& }}$ & $0.9 \pm 0.5$ & $2.3 \pm 0.7^{* *}$ & 0 \\
Grooming episodes & $3.0 \pm 0.9$ & $5.4 \pm 1.1$ & $1.6 \pm 0.4^{* * *}$ & $4.8 \pm 0.7$ \\
Rearings in closed arms & $4.8 \pm 0.8$ & $6.1 \pm 1.3^{\# \#}$ & $2.1 \pm 0.8$ & $1.5 \pm 0.8$ \\
\hline
\end{tabular}

\#, \# significant difference ( $\leq 0.05, \mathrm{p} \leq 0.01)$ between LB and SB controls; ${ }^{*}{ }^{* *},{ }^{* * *}$ between two SB groups-p $\leq 0.05, \mathrm{p} \leq 0.01$ and $\mathrm{p} \leq 0.001 ;{ }^{\& \&}$ between two LB groups $-\mathrm{p} \leq 0.01$.

and alternating visits of closed arms (which indicate the general activity level). Thus the degree of ethanol effects was much more conspicuous in SB mice. Ethanol injections changed significantly the scores for 6 out of 7 EPM behavioral indices in SB, while in LB the number of "hangings" over the border of the open arms was affected only. Thus ethanol decreased anxiety (open arms time and entries increased) and increased exploration (hangings). Numbers of grooming episodes and peepings from closed arms (could be regarded as indices of "conflict" behavior) significantly decreased and increased respectively in SB. but not in LB. Thus ethanol injections induced more distinct effect on anxiety behavior and exploration in SB than in LB mice which coincides with data from previous selection experiment [26].

Closed plus-maze test. Two factors (line and treatment) ANOVA revealed the significant influence of one or both of these factors. Table 3 presents data with post hoc Fisher LSD scores. The mean number of patrolling cycles was not high in all groups tested and actually no mice demonstrated 3 patrol cycles (maximal possible). Thus ethanol induced no drastic changes in exploration behavior. The mean number of patrol cycles decreased (not significantly) in both ethanol groups. Both factors (line and treatment) influenced the latency of the first arm entry (line $-\mathrm{F}_{1-37}=16.71368, \mathrm{p}=0.000251$, treatment $\left.-\mathrm{F}_{1-37}=12.89007, \mathrm{p}=0.001029\right)$, their interaction being also significant $\left(\mathrm{F}_{1-37}=9.12097 . \mathrm{p}=0.00477\right)$. This time index was much shorter in LB, and significantly shorter in SB ethanol (in comparison to saline groups). The shorter latency to start investigation of new environment indicates low anxiety level (which promotes more quick start of maze exploration). This coincides with EPM data - the decrease in anxiety in SB ethanol mice. Both factors influenced the time spent in the first arm (line $\mathrm{F}_{1-37}=30.99556, \mathrm{p}=0.000003$, treatment$\mathrm{F}_{1-37}=6.97277, \mathrm{p}=0.012409$, and interaction $-\mathrm{F}_{1-37}=$ $7.52515, \mathrm{p}=0.009639)$. The time spent in the arm entered first did not differ between LB groups, and was significantly higher in both SB groups. It was shorter in ethanol SBs (compared to saline group). The reduction of this time interval could be explained by the increased tendency to explore the environment and/or the increased locomotion. The similar pattern of differences had been in the indices of the 2 nd patrolling cycle (data not presented). The strategies of maze exploration were more diverse in LB (line- $\mathrm{F}_{1-37}=6.24353, \mathrm{p}=0.017460$ ) with non-significant differences between two groups. SB spent significantly more time performing stereotypical arm visits which is revealed by the influence of line factor $\left(\mathrm{F}_{1-37}=5.2817, \mathrm{p}=0.027828\right)$ and they were higher in SB (Table 3). The tendency for stereotypy was lower in SB ethanol group than in saline, but the difference (although non-significant) was reverse in LB. The tendency to perform stereotypic arm visits (and the stay in maze arms for longer time) is opposite to the tendency for maze exploration (see Methods). Thus it is possible to conclude, that LB saline mice were less disposed to stereotypy, than SB, which confirms our previous data. Data from our previous SE demonstrated the SB mice to be more prone to stereotypical arm entries [26]. Two pairs of LB and SB groups of mice in the present study differed in this trait scores in the opposite way. The increase of stereotypy in LB ethanol-treated mice is also in accordance with suggestion that their exploration behavior decreased after ethanol. The level of defecation (anxiety index) - was significantly lower in ethanol LBs.

The effects of ethanol injections were not similar in LB and SB lines. At least several of such differences in reactions to ethanol could be ascribed to initial interline differences. The time which animal spent in the center (latency) before first entry in the maze arm was shorter in both groups of LBs than in SBs, which means they differed in exploration tendency and/or in anxiety level. The LB ethanol injected mice spent less time in arms probably due to elevated locomotion and/or reduced exploration. Ethanol treated LBs also made more stereotyped visits (probably due to elevated locomotion), while 
Table 3. Mean behavior scores for F28 LB and SB mice in the closed plus maze after ethanol injection.

\begin{tabular}{ccccc}
\hline Behavioral indices & LB ethanol & LB saline & SB ethanol & SB saline \\
\hline Latency of first arm choice & $1.3 \pm 0.5$ & $2.6 \pm 0.9$ & $3.8 \pm 0.9$ & $19.6 \pm 2.9^{* * * \& \& \&}$ \\
Time in the first arm visited & $9.7 \pm 6.3$ & $9.05 \pm 6.7$ & $27.3 \pm 5.5^{\text {\&\&\& }}$ & $60.8 \pm 6.3^{* * \# \#}$ \\
Latency of arm choice (2nd patrolling cycle) & $3.25 \pm 1.6$ & $7.0 \pm 1.7$ & $0.5 \pm 1.3$ & $5.1 \pm 1.6^{*}$ \\
Time in the arms (2nd second patrol cycle) & $8.7 \pm 3.6$ & $18.1 \pm 3.8$ & $2.8 \pm 3.1^{\&}$ & $9.5 \pm 3.6^{* \#}$ \\
The duration of stereotype arm visits & $16.9 \pm 3.4$ & $10.9 \pm 3.6$ & $19.6 \pm 2.9$ & $23.5 \pm 3.4^{\#}$ \\
The number of arm visit strategies & $2.3 \pm 0.6$ & $3.0 \pm 0.6$ & $1.3 \pm 0.5^{\&}$ & $1.1 \pm 0.6^{\#}$ \\
Number of defecation boli & $0.55 \pm 0.3^{@}$ & $1.5 \pm 0.3$ & $1.1 \pm 0.3$ & $0.9 \pm 0.3$ \\
\hline
\end{tabular}

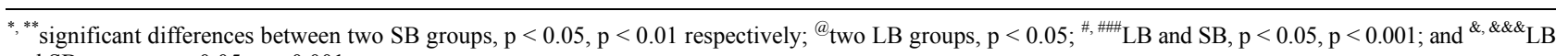
and SB groups, $\mathrm{p}<0.05, \mathrm{p}<0.001$.

in SB line the difference was opposite by sign. The latencies of entering arms during 2nd patrolling cycle in both ethanol groups were much shorter than in saline mice, and this confirms the suggestion that in both lines ethanol injection made mice less hesitating before entering maze arms. In spite of small differences between saline and ethanol groups in LB all the differences pattern agrees with suggestion that in LB ethanol group the general locomotion level was higher than in controls.

The slip funnel test. The scores of mice performance are in the Table 4. The saline LB mice used the active strategies (escape and avoidance) for longer periods than mice of SB saline group. Time and the number of avoidance episodes (animal sitting above the water) were significantly higher in LB saline mice in comparison to SB. Saline LB mice demonstrated higher number and longer time of immobility episodes than SBs. This index is usually the indicator of depressive tendencies in behavior (as in Porsolt test). The longer immobility time could be the result of fatigue as these animals stayed in the stretched posture for longer period than SB mice. Ethanol injections resulted in shorter time of avoidance and escape and in longer time of immobility, especially in SB ethanol group (Table 4).

\section{DISCUSSION}

Data presented showed that differences in brain weight, attained as the result of selection, were preserved and were still statistically significant during seven generations after the selection was discontinued.

In behavioral tests used the ethanol effects were more intense in SB mouse line. In sum SB ethanol mice initiated closed maze exploration earlier, moved more vividly (than saline mice) and demonstrated lower anxiety level in EPM as well. At the same time the respective changes were not so clear in LB mice (while scores for saline animals were higher in LB).

Different brain weights of selected RBW lines were reported to affect learning $[10,11,13,20,23,29]$ and some other behaviors, namely anxiety and stress reactivity indices $[13,17]$. The LB-SB differences were found in the ethanol injection effects in our previous SE [26]. The mean time values in ethanol SB mice were longer than in saline injected mice and approximately reverse in LB animals. Although SB ethanol mice hesitated more than saline injected animals before the start of close maze exploration, and no differences were found in LB groups.

Brain weight value is the standard characteristic which is conserved in different inbred strains across laboratories [15]. The identification of genes, which have the impact on brain size, implies QTL data on cell numbers in different brain structures (i.e. [30]). Independent loci were identified for size variation in brain areas with different degrees of correlations between them. This made authors to assume the mosaic pattern of brain development in contrast to previously postulated existence of developmental constrains [12,31]. The existence of certain alleles, involved in population differences in brain weight, is confirmed by present data which show conservative LB-SB differences under random-breeding reproduction (without supporting selection). Brain size as the genetic trait responds to artificial selection during domestication process, with domesticated forms showing smaller brains $[1,2,32]$. These changes concern farm mammals, bred for high fertility and physical parameters (and for low level of fear induced aggression). At the same time the breeding for navigation capacity, as in homing pigeons, did not induce such changes [33], and the brain weight don't increase as the result of domestic forms feralization as well [34]. Brain weight-behavior correlations could not be uniform across species - main behavioral differences between wild and domesticated vertebrate forms are numerous, and the decreased anxiety being among them $[35,36]$. The LB-SB mouse lines of our selection differed significantly in anxiety level, the SB mice being more fearful and stress-reactive. At the 
Table 4. Scores $(\mathrm{m} \pm \mathrm{SEM})$ for different behavior strategies in slip funnel test in LB and SB ethanol and saline treated animals.

\begin{tabular}{ccccc}
\hline Behavioral indices & LB ethanol & LB saline & SB ethanol & SB saline \\
\hline Time of avoidance & $38.2 \pm 7.3$ & $48.8 \pm 10.8$ & $6.9 \pm 3.1^{\& \&}$ & $10.5 \pm 6.2^{\# \#}$ \\
Time of escape & 0 & $5.4 \pm 3.8$ & $3.05 \pm 3.05$ & $23.4 \pm 10.5^{* *}$ \\
Time of immobility & $124.6 \pm 7.4$ & $112.4 \pm 11.9$ & $151.0 \pm 7.8^{\&}$ & $95.7 \pm 18.8^{* *}$ \\
Avoidance episodes. number & $1.6 \pm 0.2$ & $2.0 \pm 0.4$ & $0.5 \pm 0.2^{\& \&}$ & $0.4 \pm 0.6^{\# \#}$ \\
Escape episodes. number & 0 & $0.4 \pm 0.2^{@}$ & $0.08 \pm 0.08$ & $0.9 \pm 0.3^{* *}$ \\
Immobility episodes. number & $2.5 \pm 0.3$ & $3.0 \pm 0.4$ & $2.3 \pm 0.3$ & $2.0 \pm 0.2^{\#}$ \\
\hline
\end{tabular}

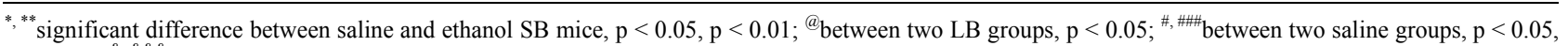
$\mathrm{p}<0.001 ;{ }^{*}, \& \& \&$ between two ethanol groups, $\mathrm{p}<0.05 . \mathrm{p}<0.001$.

same time there are not many literature sources in which cognitive abilities across two forms of one species (differing in brain weight) were compared. Those papers in which such parallels were analyzed concerned mainly rodent species [37-39], and it is obvious that numerous factors, other than brain weight exist, which influence behavior traits under comparison. At the same time the reasoning ability values in wild red foxes versus domesticated silver foxes and in wild brown rats versus domesticated laboratory rats were significantly higher [11]. Wild animals (although raised in the laboratory) were shown to be superior to their respective domesticated forms on extrapolation task performance, especially in their scores for the first task presentations (when no previous similar experience existed) [11].

\section{SUMMARY}

Investigating differences in brain weight in mice of different strains reveals the influence of such factors as sex, body weight, age, as well as methodological details of brain tissue histological processing (see R.W. Williams, [29]). It is also clear that genetic polymorphisms for brain weight differences in population are due not to rare mutations but to different frequencies of the respective alleles. Although, it is commonly accepted that the increase of brain size is the progressive evolutionary trend [2] and some proofs of this exist on the species level [11, 24]. In QTL study of brain weight suggestive QTLs for this trait were located on Chrs 15, 16 and 19, but only little overlap with the hippocampal volume QTL's was demonstrated [40]. This could signify the complexity of brain weight genetic determination.

Vulnerability to alcoholism is influenced by environmental and genetic factors which are studied extensively by using rodent models. Several QTLs and candidate genes that control ethanol responses were identified (e.g., [41]).

The differences in behavioral indices of anxiety and exploration were found in male LB and SB mice when both lines were randomly bred for seven generations. This means that differences in presumably adaptive morphological trait-brain mass-could be maintained in these two separate populations. Behavioral responses to ethanol injections were more pronounced in SB, coinciding with the data from previous selection experiment. It is possible to suggest that the genetically determined deviation of brain weight scores in the direction of lower values is maladaptive.

\section{ACKNOWLEDGEMENTS}

Supported by grants from RFBR (10-04-00891 and 13-04-00747).

\section{REFERENCES}

[1] Kruska, D.C. (1975) Comparative quantitative study on brains of wild and laboratory rats. I. Comparison of volume of total brain and classical brain parts. Journal für Hirnforschung, 16, 469-483.

[2] Kruska, D.C. (2005) On the evolutionary significance of encephalization in some eutherian mammals: Effects of adaptive radiation, domestication, and feralization. Brain Behavior and Evolution, 65, 73-108. doi:10.1159/000082979

[3] Rensch, B. (1956) Increase in learning capability with increase of brain size. The American Naturalist, 7, 81-96.

[4] Henderson, N.D. (1973) Brain weight changes resulting from enriched rearing conditions. A diallel analysis. Develop. Psychobiology, 6, 367-376. doi:10.1002/dev.420060410

[5] Markina, N.V., Salimov, R.M. and Poletaeva, I.I. (2001) Behavioral screening of two mouse lines selected for different brain weight. Progress in Neuro-Psychopharmacology \& Biological Psychiatry, 25, 1083-1110. doi:10.1016/S0278-5846(01)00169-5

[6] Rosenzweig, M.R. and Bennet, E.L. (1996) Psychobiology of plasticity: Effects of training and experience on brain and behaviour. Behavioural Brain Research, 78, 57-65. doi:10.1016/0166-4328(95)00216-2

[7] Wahlsten, D.. Bulman-Fleming, B., Wainwright, P.E., Levesque, S., Krem-Pulec, L., Bulman-Fleming, B. and 
McCutcheon, D. (1993) Effects of environmental enrichment on cortical depth and Morris-maze performance in B6D2F2 mice exposed to ethanol. Neurotoxicology and Teratology, 15, 11-20. doi:10.1016/0892-0362(93)90040-U

[8] Popova, N.V., Kessarev, V.S., Poletaeva, I.I. and Romanova, L.G. (1983) Cortical cytoarchitectonics in mice. selected for large and small brain weight. Zhurnal Vysshě Nervnoŭ Deyatelnosti, 33, 576-582.

[9] Fuller, J.L. (1979) Fuller BWS lines: History and results. In: Hahn, M.E., Jensen, C. and Dudek, B.C., Eds., Development and Evolution of Brain Size, Academic Press, New York, 518-539.

doi:10.1016/B978-0-12-314650-2.50016-1

[10] Pereplkina, O.V., Markina, N.V. and Poletaeva, I.I. (2006) The ability to extrapolate the direction of movement in mice selected for large and small brain weight: The influence of environmental enrichment. Zhurnal Vyssher Nervnoŭ Deyatelnosti, 56, 282-286.

[11] Poletaeva, I.I., Popova, N.V. and Romanova, L.G. (1993) Genetic aspects of animal reasoning. Behavior Genetics, 23, 467-475. doi:10.1007/BF01067982

[12] Hewitt, J.K., Hahn, M.E., Karkowski, L.M. (1987) Genetic selection disrupts stability of mouse brain weight development. Brain Research, 417, 225-231. doi:10.1016/0006-8993(87)90446-X

[13] Matsumoto, M., Straub, R.E., Marenco, S., Nicodemus, K.K. and Matsumoto, S., et al. (2008) The evolutionarily conserved G protein-coupled receptor SREB2/GPR85 influences brain size, behavior, and vulnerability to schizophrenia. PNAS, 105, 6133-6138. doi:10.1073/pnas.0710717105

[14] Roderick, T.H., Wimer, R.E., Wimer, C.C. and Schwartzkroin, B. (1973) Genetic and phenotypic variation in weight of brain and spinal cord between inbred strains of mice. Brain Research, 64, 345-353. doi:10.1016/0006-8993(73)90188-1

[15] Wahlsten, D., Bachmanov, A., Finn, D.A. and Crabbe, J.C. (2006) Stability of inbred mouse strain differences in behavior and brain size between laboratories and across decades. PNAS, 103, 16364-16369. doi:10.1073/pnas.0605342103

[16] Anderson, B. (1993) Evidence from the rat for a general factor that underlies cognitive performance and that relates to brain size and intelligence? Neuroscience Letters, 153, 98-102. doi:10.1016/0304-3940(93)90086-Z

[17] Markina, N.V., Popova, N.V., Salimov, R.M., Salimova, N.B., Savchuk, O.V. and Poletaeva, I.I. (1999) The comparison of levels of anxiety and stress response in mice selected for low and high brain weight. Zhurnal Vysshě Nervnoŭ Deyatelnosti, 49, 789-798.

[18] Popova, N.V., Poletaeva, I.I. and Romanova, L.G. (1981) Ability for learning and extrapolation in mice selected for different brain weight. Zhurnal Vysshě Nervnǒ Deyatelnosti, 31, 550-555.

[19] Popova, N.V., Poletaeva, I.I. and Astaurova, N.B. (1997) Selection of mice on weight of a brain. Russian Journal of Genetics, 33, 413-416.
[20] Markina, N.V., Popova, N.V. and Poletaeva, I.I. (1999) Interstrain differences in the behavior of mice selected for greater and lesser brain mass. Zhurnal Vysshě Nervnǒ Deyatelnosti, 49, 59-67.

[21] Popova, N.V., Kessarev, V.S., Poletaeva. I.I. and Romanova, L.G. (1983) Cortical cytoarchitectonics in mice. selected for large and small brain weight. Zhurnal Vysshě Nervnoĭ Deyatelnosti, 33, 576-582.

[22] Elias, M.F. (1969) Differences in spatial discrimination reversal learning for mice genetically selected for high brain weight and unselected control. Perceptual and Motor Skills, 28, 707-712. doi:10.2466/pms.1969.28.3.707

[23] Gonsiorek, J.C., Donovick, P.J., Burright, R.G. and Fuller, J.L. (1974) Aggression in low and high brain weight mice following septal lesions. Physiology \& Behavior, 12, 813818. doi:10.1016/0031-9384(74)90018-3

[24] Popova, N.V. and Poletaeva, I.I. (1983) Ability to solve extrapolation problems in mice selected for different brain weights. Zhurnal Vysshě̆ Nervnoŭ Deyatelnosti, 33, 370-372.

[25] Popova, N.V. and Poletaeva, I.I. (1985) Avoidance conditioning in mice with different brain weight. Zhurnal Vysshe ̌̌ Nervnoĭ Deyatelnosti, 35, 170-172.

[26] Salimov, R.M., Markina, N.V., Perepelkina, O.V., Maǐskiı̌, A.I. and Poletaeva, I.I. (2003) Rapid tolerance to ethanol and high voluntary alcohol consumption in mice selected for brain weight. Zhurnal Vysshě Nervnǒ Deyatelnosti, 53, 100-106.

[27] Salimov, R.M. (1999) Different behavioral patterns related to alcohol use in rodents: A factor analysis. Alcohol, 17, 157-162. doi:10.1016/S0741-8329(98)00049-4

[28] Salimov, R.M., McBride, W.J., McKenzie D.L., Lumeng, L. and Li, T.-K. (1996) Effects of ethanol consumption by adolescent alcohol-preferring $\mathrm{P}$ rats on subsequent behavioral performance in the cross-maze and slip funnel tests. Alcohol, 13, 297-300. doi:10.1016/0741-8329(95)02060-8

[29] Williams, R.W. Measuring brain weight (Program). http://www.nervenet.org/iscope/mbl_10.html

[30] Williams, R.W., Strom, R.C. and Goldowitz, D. (1998) Natural variation in neuron number in mice is linked to a major quantitative trait locus on Chr 11. The Journal of Neuroscience, 18, 138-146.

[31] Hager, R., Lu. L., Rosen, G.D. and Williams, R.W. (2012) Genetic architecture supports mosaic brain evolution and independent brain-body size regulation. Nature Communications, 3, 1079. doi:10.1038/ncomms2086

[32] Kruska, D.C. (1987) How fast can total brain size change in mammals? Journal für Hirnforschung, 28, 59-70.

[33] Rehkämper, G., Frahm, H.D. and Cnotka, J. (2008) Mosaic evolution and adaptive brain component alteration under domestication seen on the background of evolutionary theory. Brain, Behavior and Evolution, 71, 115126. doi: $10.1159 / 000111458$

[34] Röhrs, M. and Ebinger, P. (1999) Wild is not really wild: brain weight of wild domestic mammals. Berliner und Münchener Tierärztliche Wochenschrift, 112, 234-238. 
[35] Augustsson, H., Dahlborn, K. and Meyerson, B.J. (2005) Exploration and risk assessment in female wild house mice (Mus musculus musculus) and two laboratory strains. Physiology \& Behavior, 84, 265-277. doi:10.1016/i.physbeh.2004.12.002

[36] Driscoll, C.A., Macdonald, D.W. and O’Brien, S.J. (2009) From wild animals to domestic pets. An evolutionary view of domestication. PNAS, 106, 9971-9978. doi:10.1073/pnas.0901586106

[37] Fonio, E., Benjamini, Y., Sakov, I. and Golani, A. (2006) Wild mouse open field behavior is embedded within the multidimensional data space spanned by laboratory inbred strains. Genes, Brain and Behavior, 5, 380-388. doi:10.1111/j.1601-183X.2005.00170.x

[38] Lewejohann, L., Pickel, T., Sachser, N. and Kaiser, S. (2010) Wild genius-Domestic fool? Spatial learning abilities of wild and domestic guinea pigs. Frontiers in
Zoology, 7, 9. doi:10.1186/1742-9994-7-9

[39] Stuermer, I.W. and Wetzel, W. (2006) Early experience and domestication affect auditory discrimination learning, open field behaviour and brain size in wild Mongolian gerbils and domesticated laboratory gerbils (Meriones unguiculatus, forma domestica). Behavioural Brain Research, 173, 11-21. doi:10.1016/j.bbr.2006.05.025

[40] Peirce, J.L., Chesler. E.J., Williams, R.W. and Lu, L. (2003) Genetic architecture of the mouse hippocampus: Identification of gene loci with selective regional effects. Genes. Genes, Brain and Behavior, 2, 238-252. doi:10.1034/j.1601-183X.2003.00030.x

[41] Ziebarth, J.D., Cook, M.N., Wang, X., Williams, R.W., Lu, L, and Cui, Y. (2012) Treatment-and population-dependent activity patterns of behavioral and expression QTLs. PLoS One, 7, e31805. doi:10.1371/journal.pone.0031805 